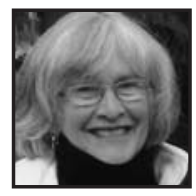

\title{
Distributed Leadership: Would Knowing More About It Then Have Produced a More Effective Professional Development Design?
}

\author{
Elizabeth Walcot, Université de Sherbrooke
}

\begin{abstract}
This article is a personal reflection on the relationship between leadership and the results of a professional development project. The project was designed to change elementary teachers' instructional interventions in text production from a conventional approach to one more congruent with process writing. This reflection is framed by the current literature on "distributed leadership" which was not available when the project began or during the life of the project. It gives some suggestions about how the project might have been organized differently, as well as how interaction with the participants might have been made more explicit.
\end{abstract}

hange is an important topic for those involved in improving student achievement in various domains. Several years ago I directed a project, where the goal was to shift English elementary teachers' instructional practices in the domain of text production or writing to one which would take into account a process approach to writing. A process approach to writing is based on how writers compose texts in "real life" writing situations, which differs greatly from how writing typically has been taught in schools (Atwell, 1998). The project was embedded in ongoing professional development with a flexible structure so that the project could respond in a variety of ways to teachers' needs. It included large and small group discussions, opportunities for team teaching and for modeling and coaching by others within the school and by me. The administration supported the project through release time given to the teachers and the specialists. Teachers were 
encouraged to take the leadership in any of the activities, but were very reluctant to do so. The change in instructional practices after three years was not extensive. Although some reasons for this result were clear, questions remained, including: What had I not taken into account when the project was first or progressively developed? This article is my attempt respond to this question by exploring factors related to leadership, which were not well understood at the time and, until recently, have not been well researched.

During the time of the project (1998-2001), it seemed that everyone went into it with the best of intentions. The teachers appeared to want to learn more about process writing through teaching students to brainstorm, draft, revise, edit and to control the process. They had a variety of valid questions:

- How does one integrate new students who have not learned certain strategies or skills into a group where many of the students have integrated this instruction?

- How does one balance mastery vs. moving on to new tasks? What happens to the student who has not solidified previous strategies, information, or skills?

The teachers embarked on learning instructional interventions appropriate for their students and tried to answer some of their own questions. In addition, the administration and the facilitators had a strong belief, backed up by the research at the time, that there were specific strategies that teachers should learn to teach and that, once learned by students, would improve writing performance. The project was designed within a framework based on the professional development literature. It was conducted over time, had various formats, focused on student learning, and provided for feedback. The project appeared to begin with some of the influential change process factors in place.

My expectation was that the change targeted by the project-a move to the teaching of process writing - was bound to be positive for a majority of the participants. This was not what happened! The most that can be said is that the move to changing instructional practices was somewhat positive for two or three out of the eight persons involved. Again the question remains as to why did I not get better results, given the professional development framework and the expertise of the facilitators. One can explore multiple factors within the participants themselves, within the context of professional development and within the institutional structure. In this article, I will address issues connected to leadership, first within the educational 
change literature. Then I will use this literature to frame my reflections on the consequences of leadership decisions within the project. Finally, I will explore what I might have done differently.

\section{Educational Change Literature}

Much has been written about educational change since the early 1990 s. Within this literature, the changing of teachers' instructional practices to improve student performance has been one of the important focal points. The changing of certain instructional practices has been well researched. These include becoming more learner-centred, introducing basic skill activities (e.g., increasing phonemic awareness), widening pedagogical content knowledge (e.g., in mathematics and science) and implementing new pedagogical practices (e.g., problem-based learning). The literature indicates that teachers can effectively learn innovative practices within a variety of frameworks: ongoing professional development, action research, and in small, formal or informal collaborative groups.

However, research results indicate that not all such initiatives have been successful or were sustained. Unsuccessful results were variably attributed to cognitive characteristics of teachers (e.g., the strength of contradictory beliefs, low self-efficacy for implementing the initiative and the inability to think critically about their instructional practices) and to the contextual framework of the classroom (e.g., time or schedule constraints and demands of the curriculum). Unsustained results were seen when teachers reverted to previous practices once ongoing collaborative opportunities to discuss and solve problems related to the practice were not continued and when administrative leadership was not provided (Mclntyre \& Kyle, 2006). In order to better understand unsuccessful or unsustained initiatives, this article will look at administrative and teacher leadership as influential factors in the change process.

The term "leadership" refers to the practice of leading. Leadership involves complex interactions between leaders and other persons within a particular context. Under consideration in this article is the school context, which includes (a) the organizational structure, (b) the power structure as manifested by the administration, and (c) the school's interactive culture (e.g., collegial/collaborative or isolated/selfprotective). 


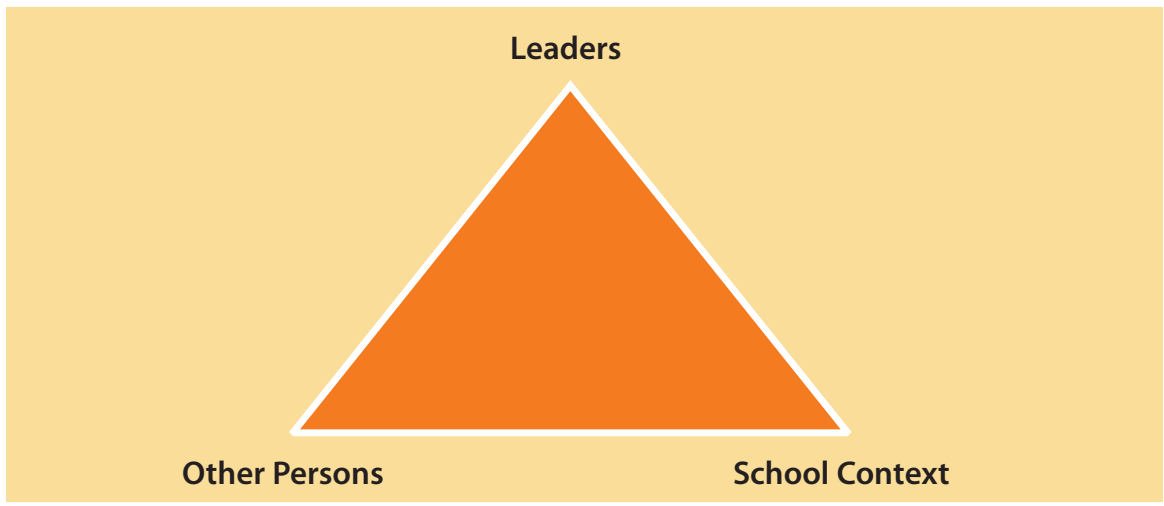

Fig. 1: Leadership components

School leadership has traditionally been identified with management and organizational tasks assigned to the principal, which he or she may delegate to others. This is a hierarchical model, where principals are seen as the decision makers, but not as the providers of instructional or pedagogical direction and guidance. In such a model, these latter tasks are usually delegated to instructional consultants at the elementary levels (often located in central offices away from the schools to which they consult), and to department heads at the secondary level.

In contrast to the hierarchical model, current approaches to leadership often talk about "distributed leadership" (Leithwood et al., 2007) or "distributing leadership" (Harris, 2006). Both terms refer to cases where pedagogical leadership is not delegated but identified with different persons at different levels and in different domains within the school structure. Distributed leadership evolves and changes in order to respond to the need for specific types of leadership practices within diversified contexts and time lines. Harris $(2006$, p. 3$)$ describes distributing leadership as an organic process involving administrators, teachers and other staff within the school.

Within the distributed leadership framework, Spillane and Temperley (2004, p. 3) label "other persons" as "followers," but not in the traditional passive role associated with followers. These researchers talk about the relationship between leaders and followers as a way of co-producing leadership, confounding the usual distinction between leaders and followers. Both contribute to leadership in the change process. To support this view of leadership, the term 'leader' refers not only to those who are already leading, but also to those who have the potential to lead. Potential is defined as having certain personal characteristics (e.g., problem solving) and individual learning goals, (e.g., the improvement of student performance in particular 
fields). Persons with potential for leadership or holding actual leadership positions are identified as part of an organization's strength when change is initiated.

In distributed leadership, the school administration or principal remains critical to change in ways that are not dissimilar to traditional views of leadership. They are targeted as being pivotal within the schools' change processes, because they are in a position to influence the direction and pace of teachers' learning activities. They do this through allocating resources, in terms of money, time, staff, space and technological support. In addition, principals need to create the infrastructure necessary for training or collaboration, and ensuring continuity. They can guard against excessive other demands made on teachers' time and can institute a process of teacher recognition for those showing particular effort or making a specific contribution to the change process (Leithwood et al., 2007).

However, in the distributed leadership framework, the influence of the administration's involvement goes further than the assignment of funds, the provision of release time and attention to the structural organization. According to current researchers, leadership at the administrative level entails collaboration with teachers, the development of shared understanding of the change to be implemented and acceptance of common goals that are driven by student needs. As part of this ongoing process, the evaluation of the effectiveness of the change on student performance is critical and setting up the data gathering process is an important component (Leithwood, Louis, Anderson, \& Wahlstrom, 2004; Timperley, 2006). This process implies that an administrator needs to be personally implicated in the project, so that decision making, important for identifying student needs, data gathering and evaluation, are joint endeavors. Thus, the administration's decision concerning active involvement in the professional development process as a peer rather than an authority figure can have a positive influence on innovative initiatives. Correspondingly, the lack of personal involvement can reduce the impact and sustainability of the change process (Fullan, 2001; Walkington, 2002).

While the administration's participation in the give and take of discussions and feedback is a significant factor in the success of the change process, the implication of this nontraditional role is that leadership is broad-based and extended to other members of the school community. Most frequently, persons taking varied leadership positions are teachers. Sometimes this happens formally by someone being named as the leader of a specific group, and sometimes informally as a leader arises out of a collaborative group working towards certain goals. Recent research results are beginning to explore factors positively contributing to teacher leadership within a process of successfully implementing new instructional practices. 


\section{Inquiring into Teacher Leadership}

Muijs and Harris (2006) have recently written about five dimensions of teacher leadership within the distributive framework:

The first was shared decision-making where teachers were given responsibility to make decisions on behalf of the school on important developmental work. The second was a form of collaboration in which they operated collegially for the prime purpose of securing certain outcomes linked to improving teaching and learning. The third was active participation where teachers understood teacher leadership in terms of being actively involved in core developmental tasks and being participants in the process of school improvement. The fourth was professional learning in which teachers are learning individually and with colleagues. The fifth was leadership as activism where teachers engaged with issues on behalf of the school in order to directly affect change and development. (pp. 964-965)

The five dimensions put forward by Muijs and Harris form the framework of my reflections on what happened, and what might have been done differently.

Although shared decision making is identified as the first dimension of effective distributive leadership, this is dependent on principals encouraging and supporting changes in power structures (Leithwood et al., 2007). Since principals do not always have a collegial administrative style, this has been seen as problematic. Administrators may feel threatened by others taking control and react negatively, by undermining any endeavors over which they feel they have little authority. Thus, for teachers to take leadership positions, certain informal and formal interrelationships between the principal and the teacher leaders need to be in place. There must be mutual respect and trust, as well as clarification of the roles and decision-making powers remaining with the formal leader (i.e., a principal) versus those devolving to new leadership roles within a distributed leadership framework. Once these conditions are accepted and acted upon, the capacity of teachers to make decisions has been identified as empowering teachers and positively influencing the change process (Muijs \& Harris, 2006).

What was the impact of the shared decision dimension? When the project was initiated I was responsible for it. The principal, who was very supportive of teacher and teacher initiatives, was not directly involved. This interfered with lines of 
communication and responsibility which could have been avoided had we both been co-directors.

The second dimension relies on the creation of collaborative working groups or professional development communities (Stoll \& Seashore Louis, 2007). The ability to collaborate in professional learning communities, while also providing leadership, is critical. Collaboration requires an atmosphere of collegiality and trust. This assumes that teachers and teacher leaders understand and use collaborative behaviours, including showing respect for differing opinions and using discourse that focuses on the tasks at hand rather than on feelings. Without this understanding, a strong collegial foundation and social cohesion are less likely to be established. Groups in such a situation may struggle and not be productive. These results were supported by research published broadly at the time the project was implemented.

Recent studies have looked at the negative impact of collegiality. Collegiality may also produce informal or unstructured small groups. These may compete through establishing different priorities and time frames. They may have poorly defined goals and accountability structures. In such conditions, the leaders emerging from each group may not exhibit those characteristics that are identified with strength and effectiveness: good ability to problem solve around the content, to negotiate differences, to motivate others, to stay organized and to network with other leaders within the school. The result of informally evolving leadership may be the maintenance of the status quo (Harris, Leithwood, Day, Sammons \& Hopkins, 2007).

The groups in this professional development project were formally structured along the levels of the students' writing abilities - those with students at the early stages in one group, while those of more advanced students in another. Sometimes the two groups were combined when specific information common to them both was presented. Since a number of the participants were reluctant to share information little collegiality or trust developed. These teachers were good problem solvers, but had little previous experience in negotiating differences or motivating others. I tried focusing on the actions, modeling language and respect, but was not successful at positively influencing the interpersonal interactions.

Expert facilitators are crucial to the creation of collaborative environments, especially when change is the objective and teachers are unfamiliar with using the language of trust. As a facilitator I could have attended more carefully to the issue of trust and been more explicit about how the role of trust affects the project goals. 
Some mentoring or training along these lines would have made me better able to reach out effectively to the other participants.

The third dimension refers to active involvement in core development tasks, such as monitoring, clarifying, negotiating and deciding. In order to be actively involved in these tasks, teacher leaders must be able to coordinate and integrate their decision making with others at the different levels of leadership. This requires a formal and organized form of networking of school leaders. Unlike hierarchical models where the reporting structure is clear, the distributed leadership model implies that problem solving and decisions are made laterally and vertically throughout the school's structure (Harris, Leithwood, Day, Sammons \& Hopkins, 2007). This complicates the understanding of the change proposed, the communication and the consistency of goal orientation and the evaluation. Thus, networking of the different layers of leadership is a crucial but complex endeavour.

Even when leadership is planned and networks of communication, professional support and sharing are established, ownership of the change process may not be attained. As Fullan (2004) points out, sometimes the networks are too numerous. Rather than supporting the process, they obfuscate the tasks and goals of the leaders and result in a lack of focus. This detracts from investment in the network, resulting in a sharing of beliefs rather the constructing of negotiated and effective change. In addition, for networks to be effective, there must be a plan for the teacher leaders to bring ideas back to the original collaborative groups (Fullan, 2004). Networking may be effective but needs to be closely monitored to check that it contributes positively to the "core development tasks" described by Muijs and Harris (2006).

Although the professional development project was designed to give teachers some control over the content, they did not have control over the "monitoring, clarifying, negotiating or deciding." That was my responsibility. In addition, teachers had no networking responsibility, either with the staff as a whole, or with the other leaders. This was a major drawback. On the surface, the organization and content were designed to respond to teachers' expressed needs, but, in reality, they had no real control over the process, including no evaluative responsibility with either their peers or their superiors; no open communication of what they had learned and no channel through which to express any dissatisfactions. This lack of consistency between the talk and the action may have contributed to the teachers' lack of engagement in the process of change. 
The fourth dimension mentioned is the emphasis on learning. From a constructivist perspective, teacher learning has been identified as an active process. This implies ongoing social interaction as teachers define and clarify the transformations being suggested and adapt these ideas using their own experience in classrooms or schools. Learning requires that these new directions or changes in instructional practices be evaluated and the results used to make the change desired more effective. Teacher learning requires active engagement in a process of personal growth.

In order for a change process to have an impact on student learning, all the staff in a school must understand that they are learners in the process. A recent study (Timperley, 2006) found that when administrators or teacher leaders did not pay attention to their own learning, the results showed a lack of focus on student achievement and more of a focus on teachers' growth in collaboration. In order to positively affect student outcomes, the individual leaders, whether an administrator, department head or teacher leaders, must each set their own learning goals and recognize progress towards these goals.

For most of the teacher participants in this project, viewing themselves as learners was not a common or familiar stance. Historically, the approach to teacher learning in this context was the one-day workshop or attendance at conferences with little or no follow-up. On an individual basis, there were only a small number of participants who were committed to ongoing learning. So although initially teachers appeared to be positive, the project did not engender or build a commitment to learning about process writing. Perhaps it would have helped if I as the group facilitator had arranged explicit discussions about the importance of learning objectives in this professional development format. A more explicit focus on learning might have made a difference.

The literature stresses the importance of improved student achievement for teachers' to be motivated to change their instructional practices. The school itself did not demand common evaluative procedures for writing, which meant that the link with improved student achievement in this domain could not be definitivley documented. The result was that the connection between innovative instructional interventions and higher achievement outcomes could not be made. Understandably, this may have had an impact on the participants' motivation.

Finally, the fifth dimension refers to the importance of having effective leaders acting as "system thinkers in action" at all levels of distributed leadership (Fullan, 2004a). Harris (2006) refers to this as "crossing boundaries" (p. 2). Even when the 
change focus is on classroom instructional practices, leaders have to see and understand the change required in terms of the school or district system: What are the goals? What are the implications for others within the school building? What are the necessary shifts in the school's organization and structure to make the change more effective? How do the leaders and others involve parents and students in the process? In addition to the changes brought about within the classroom, sustainability requires a broad approach to the conditions that support this change.

The culture in the school where the project took place was not one of collaboration or involvement in wider issues. The focus was on what happened in the teachers' specific classrooms. Although there was some sharing of materials, teachers were isolated and seldom, if ever, visited one another's classrooms. This isolation extended to a lack of agreement on commonly accepted standards or rubrics. The teachers were not "system thinkers in action" (Fullan, 2004b) and this became a major barrier to achieving the project's goals of increased communication and agreement on a curriculum for teaching writing.

Leadership has always been recognized as a component of the change process. Only recently have researchers tried to describe this concept in ways that show how teachers' involvement in leadership can positively have an impact on instructional practices and student performance. In the current context, distributed or distributing leadership is one of the attempts to better understand what leadership entails.

In this school, as in many others, the teachers had not been exposed to a culture of sharing nor had they had opportunities to visit each others' classrooms. They had not had the occasion to become "system thinkers in action" and it is likely that this limited their professional growth in this project.

For an administration, distributed leadership involves sharing the responsibility and authority for the change effort. It implies a restructuring of leadership within the school context, keeping certain responsibilities within the administrative level (i.e., funding, scheduling), while sharing others (i.e., goal setting, decision making and creating a school culture of trust and respect) and adding others (i.e., involvement in their own learning as peers in discussions and professional development projects).

For teachers, distributed leadership requires a shift away from a hierarchical structure. Teacher leadership entails active involvement with one's peers and colleagues in trusting and respectful learning communities, which support the coordi- 
nation of the group's goals and decision making with others within the school's leadership positions. As with the administration, teacher leadership implies immersion in a process of personal learning. Finally, teacher leadership requires the ability to cross barriers-the four walls of the classroom, informal cliques within the staff, and hierarchical structures.

\section{Conclusion}

The literature on distributed leadership assumes a school restructuring. Administrative functions do not change easily and certainly not without planning and an effective leader who strongly believes that sharing decision making can positively influence students' learning. This shift was not possible within the school in which I was involved at that time, which raises another question:Would the outcomes have improved if I had designed the project along more traditional lines? This might have meant keeping the design components that focused on the type and organization of the sessions (i.e., flexible, ongoing, small and large group meetings, as well as modeling/coaching), but organizing the work to be less teacher-centered. Being more explicit about my expectations would have involved making decisions relative to goals and content. It would not have been teachers who determined the pace, the content and the roles of members within the group. This would have been my responsibility. However, the current research on "distributed leadership," suggests that such a traditional approach might have produced some surface or short-term change, but it is unlikely that any changes would have been sustained.

I made assumptions about how others would perceive my leadership within the project. I viewed myself as a teacher leader and facilitator but not an expert in the teaching of writing at the elementary level. The other participants saw me as the "expert" and as someone with a certain level of authority. As these opposing perspectives on my leadership role were not directly addressed, they caused problems in terms of expectations and evaluation. If I produced material that they could see themselves using in classrooms, the participants were happy. If I expected that they would take ownership through developing common frameworks for teaching and evaluating writing or developing their own material, the participants were silent. Our expectations were different, and, thus, one of the consequences was that we evaluated the success of the project from totally different perspectives. 
The focus on distributed leadership as a concept underlying change has helped me to broaden my understanding of the role of leadership in any professional development project, not only within this specific project but also within the school and, even more widely, within a district. If we want teachers to take on the leadership as part of the change processes, then they need to authentically engage in decision making. This contradicts the inherent beliefs in many administrative roles, which continue to be identified with control and decision making. A change from traditional to distributive leadership cannot happen without the shifting of teachers' and administration's beliefs and roles.

\section{References}

Atwell, N. (1998). In the Middle. Portsmouth, NH: Heinemann.

Fullan, M. (2004a). Change forces: Leadership and sustainability. Toronto, ON: University of Toronto, Ontario Institute for Studies in Education.

Fullan, M. (2004b). Leadership and sustainability: System thinkers in action. Thousand Oaks, CA: Corwin.

Fullan, M. G. (2001). The new meaning of educational change (third ed.). New York: Teachers College.

Harris, A. (2006). Distributing leadership in schools: Challenge or possibility. Retrieved January 28, 2008, from http://slc.educ.ubc .ca/eJournal/Issue7/Authors/Alma_Harris. html

Harris, A., Leithwood, K., Day, C., Sammons, P., \& Hopkins, D. (2007). Distributed leadership and organizational change: Reviewing the evidence. Journal of Educational Change, 8(4), 337-347.

Leithwood, K., Louis, K. S., Anderson, S., \& Wahlstrom, K. (2004). Review of research: How leadership influences student learning: University of Minnesota, Center for Applied Research and Educational Improvement and University of Toronto, Ontario Institute for Studies in Education.
Leithwood, K., Mascall, B., Strauss, T., Sacks, R., Memon, N., \& Yashkina, A. (2007). Distributing leadership to make schools smarter:Taking the ego out of the system. Leadership and Policy in Schools, 6(1), 37-67.

McIntyre, E., \& Kyle, D.W. (2006). The success and failure of one mandated reform for young children. Teaching and Teacher Education, 22(8), 1130-1144.

Muijs, D., \& Harris, A. (2006). Teacher led school improvement: Teacher leadership in the UK. Teaching and Teacher Education, 22(8), 961-972.

Stoll, L. \& Seashore Louis, K (Eds.) (2007). Professional Learning communities: Divergence, depth and dilemmas. New York: McGraw Hill.

Timperley, H. S. (2006). Learning challenges involved in developing leading for learning. Educational Management Administration \& Leadership, 34(4), 546-563.

Walkington, J. (2002). A process of curriculum change in engineering education. European Journal of Engineering Education, 27(2), 133-148. 


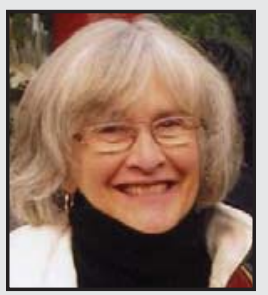

Elizabeth Walcot, Ph.D. completed her studies at the Université de Sherbrooke, Sherbrooke, QC, Canada. Her research interests include the teaching/learning of writing and the use of technology to support the writing process and reading comprehension. She has served as the President of the Board of Directors of Learning Disability Association of Canada. She is presently serving as President of the Board of Directors for Centre for Literacy in Montreal and as a member of the Comité consultative du Conseil d'Administration sur les Services aux Personnes Handicappée de Bibliothèque et Archives nationals du Québec. Finally, she volunteers with two teachers at the Montreal Oral School for the Deaf to improve the students' oral language including reading comprehension and written expression. 